The donkeys and goats, so universal in the north, are similarly to be penned and manure prepared in the same way. On this system a family can easily farm twelve acres.

A visit to the experimental farm near Kano, which fortunately took place after nearly four inches of rain had fallen during the night, convinced me that the introduction of the plough into the light land of northern Nigeria is liable to prove a curse which will more than outweigh the blessing conferred by mixed farming. Every furrow is a water course taking off the needed water, every one an incipient erosion gully (Fig. 1). Cross ploughing at intervals is not a remedy a new gully is formed-nor is contour ploughing in this gently undulating plain land sufficient.

Fortunately the local cultivator has already evolved a system which points the way. Instead of the yam hills of the south are ridges (from three to six feet apart and from nine inches to thirty inches high) crossed at intervals by ridges at right angles. Instead of the long straight plough-furrow the result is a series of isolated basins. Into these are swept the finer particles of soil during a storm but no soil is lost, for the basins fill with water, which later seeps away. Only rarely does a ridge give way, and even so it is easily repaired. When the land is prepared for the next year's crop the new ridge takes the place of the previous hollow, so that the soil is well mixed again (Fig. 2). The same result can be achieved by ploughing, if the plough is lifted at intervals. This can readily be done with the light plough used. It is clear that the careful use of cover-crops (a dirty farm is probably better than a well-weeded one), the restoration of fertility by leguminous crops, and the maintenance of wind breaks or 'protection forests' (the Forestry Department in conjunction with the French authorities are to preserve the remaining tracts of scrub and woodland along the international border) are all necessary in addition, as well as the control of areas where erosion is already serious.

If America could invent a plough which will imitate the Nigerian system by replacing the long furrow by a series of isolated elongated basins, one at least of her major problems in the dry lands of the Middle West might be solved.

\title{
Observations made in the Highest Stratosphere Flight
}

\begin{abstract}
A DETAILED account has been published* of the scientific results of the flight of Explorer II, in which, on November 11, 1935, Major A. W. Stevens and Captain O. A. Anderson ascended to a height of 72,395 feet, or 12.7 miles. This is the greatest height ever reached by man.

To prevent any possibility of a repetition of the disastrous explosion which occurred during the descent of Explorer $I$, it was decided to fill Explorer $I I$ with helium, even although this meant making the balloon considerably larger. The difficulties of filling these huge balloons are very considerable, and the most suitable place that could be found for carrying out this operation was the "Stratosphere Bowl", a natural crater in South Dakota providing complete shelter from the wind. It was intended to make the ascent in June, but when the balloon was half full the fabric burst round the 'rip-panel'. This panel was to be used for rapid deflation when the balloon landed. As a result of this mishap, the balloon had to be considerably modified and was not ready until October, and suitable weather for the ascent did not occur until November.

\footnotetext{
* "The National Geographic Society U.S. Army Air Corps Strato-
} sphere Flight of 1935 in the Balloon 'Explorer II'." (Contributed Technical Papers, Stratosphere Series, No. 2.) (Washington : Nationa] Geographic Society, 1936.)
\end{abstract}

A great many people co-operated to make this flight a success. Measurements were made of the angular distribution of cosmic rays, and the nature of the corpuseles forming them, the distribution of ozone, the conductivity and constitution of the air in the stratosphere, and of the intensity of solar and terrestrial radiation. It was proved that the spores of certain moulds and bacteria can and do exist in the stratosphere, and an attempt was made with rather inconclusive results to find whether the great intensity of cosmic radiation would accelerate mutation in Drosophila.

\section{Cosmic Rays}

The cosmic ray measurements were for the most part carried out under the direction of G. F. Swann. For measuring the angular distribution of cosmic rays a battery of ten cosmic ray telescopes and 210 Geiger counters were used. Five of the telescopes were shielded with lead. The results of this work are illustrated in Fig. 1. In the case of the vertical telescopes, maxima were obtained at the heights corresponding to one and two metres of water below the top of the atmosphere respectively, but these maxima were less pronounced at greater zenith angles. The existence 
of a maximum in the ionization - depth curve shows that it is secondary and not primary particles which do most of the ionizing, and the depth of the maximum gives a measure of the range of these particles. The cause of the second maximum is rather obscure.

It was unfortunately considered impracticable to take cloud chamber photographs of cosmic rays although a special chamber was ready to be taken up. This seems a great pity and in the opinion of the reviewer more useful information would have been obtained by taking up a cloud chamber than a wireless transmitting set. Instead, the balloon carried a number of photographic plates specially prepared with pinacryptol yellow. Such plates

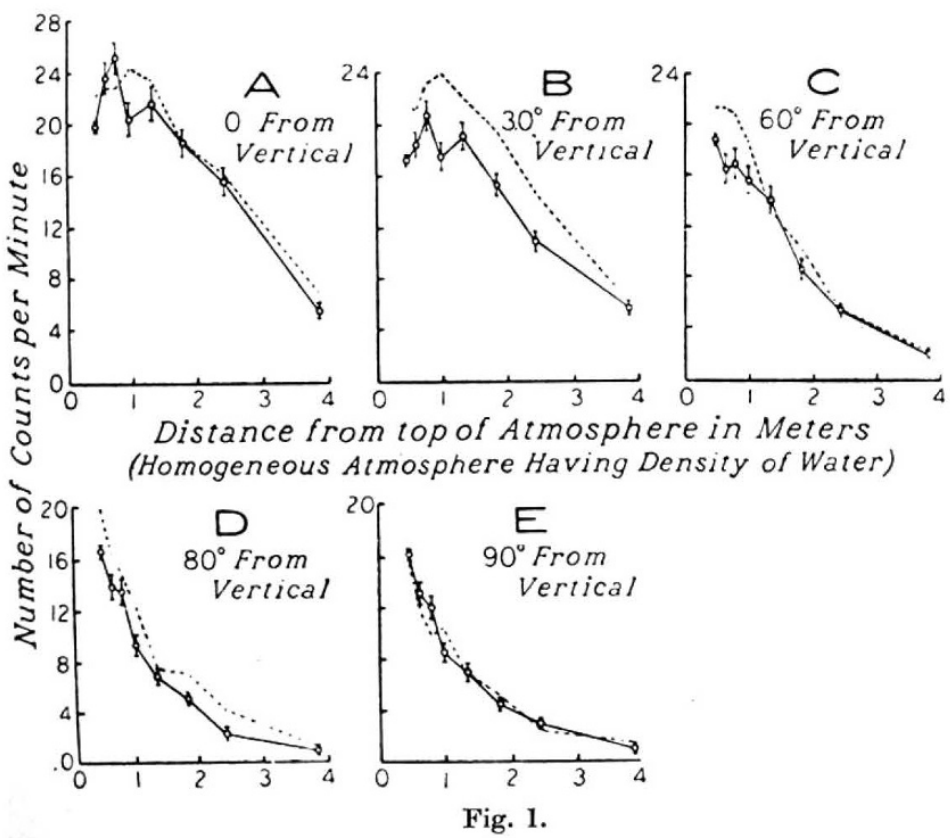

IONIZATION-DEPTH CURVES. THE FULY LINES REFER TO SHIFLDED, THE DOTTED LINES TO UNSHIELDED, COUNTERS. this means. balloons.

of the energy must be carried by photons, positrons and electrons, which cannot be detected by

The technique which has been evolved for using photographic plates as continuously acting cloud chambers should prove very valuable and, as there is no need to have a manned balloon to carry the plates into the stratosphere, it is to be hoped that this work will be continued with unmanned

\section{Ozone}

The ozone measurements were made with an ultra-violet spectroscope developed by O'Brian, the amount of ozone between the observer and the sun being deduced from the absorption of the ultra-violet rays. As it was not possible to keep the instrument pointed directly at the sun, sunlight was scattered into the instrument by a diffusing sphere. This also scattered sky light into the instrument, but the effect of this seems to have been neglected. A second instrument was carried to make spectrograms of the sky $9^{\circ}$ above the horizon, and with this it was hoped to deduce the distribution of ozone above the balloon, although it is not very clear how $O$ 'Brian intended to do this. The second instrument might have been better employed on the ground to measure the changes in the total amount of ozone during the flight.

It is evident from Fig. 2 that the distribution of ozone found by O'Brian on the flights of Explorer $I$ and $I I$ do not agree well with those found by Regener with unmanned balloons,

serve as continuously acting cloud chambers, in that ionizing particles leave characteristic tracks when the plates are developed; moreover, by counting the grain spacing under a microscope, it is possible to distinguish the track of a proton from that of a heavier particle. The plates were packed in flat nitrogen-filled rubber bags, and some of them were placed almost in contact with compounds of different elements so that the effect of bombardment of these elements by cosmic ray particles could be observed. Locker and Rumbaugh concluded that $\alpha$-particles form at most a fraction of 1 per cent of the ionizing particles. The neutron intensity at an equivalent of half a metre of water is more than 2,000 times as great as at six metres, and at this height they form a considerable proportion of the ionizing particles although they carry less than 2 per cent of the energy. The rest nor with those found by Götz, Meetham and Dobson at Arosa from measurements on the ultra-violet spectrum of the zenith sky at sunset. His distribution agrees more closely with those found by Meetham at Tromsø in latitude $69^{\circ} 40^{\prime}$ than that at Arosa, which is at about the same latitude, namely, $40^{\circ}$. There was little ozone near the ground or below $15 \mathrm{~km}$., and the maximum concentration was at $22 \mathrm{~km}$., almost exactly the height reached by the balloon. The other workers found much larger concentrations near the ground.

\section{Conductivity}

Knowledge of the electrical conductivity of the atmosphere in fine weather is of great importance as it enables us to find the potential of the Heaviside layer. If we assume that the vertical air-earth 
current is constant and equal to $i$ units per sq. cm., then if $\lambda$ is the total conductivity (equal to the sum $\left.\lambda_{+}+\lambda_{-}\right)$, the potential is $i \int_{0}^{B} \frac{\lambda^{-}}{}$.

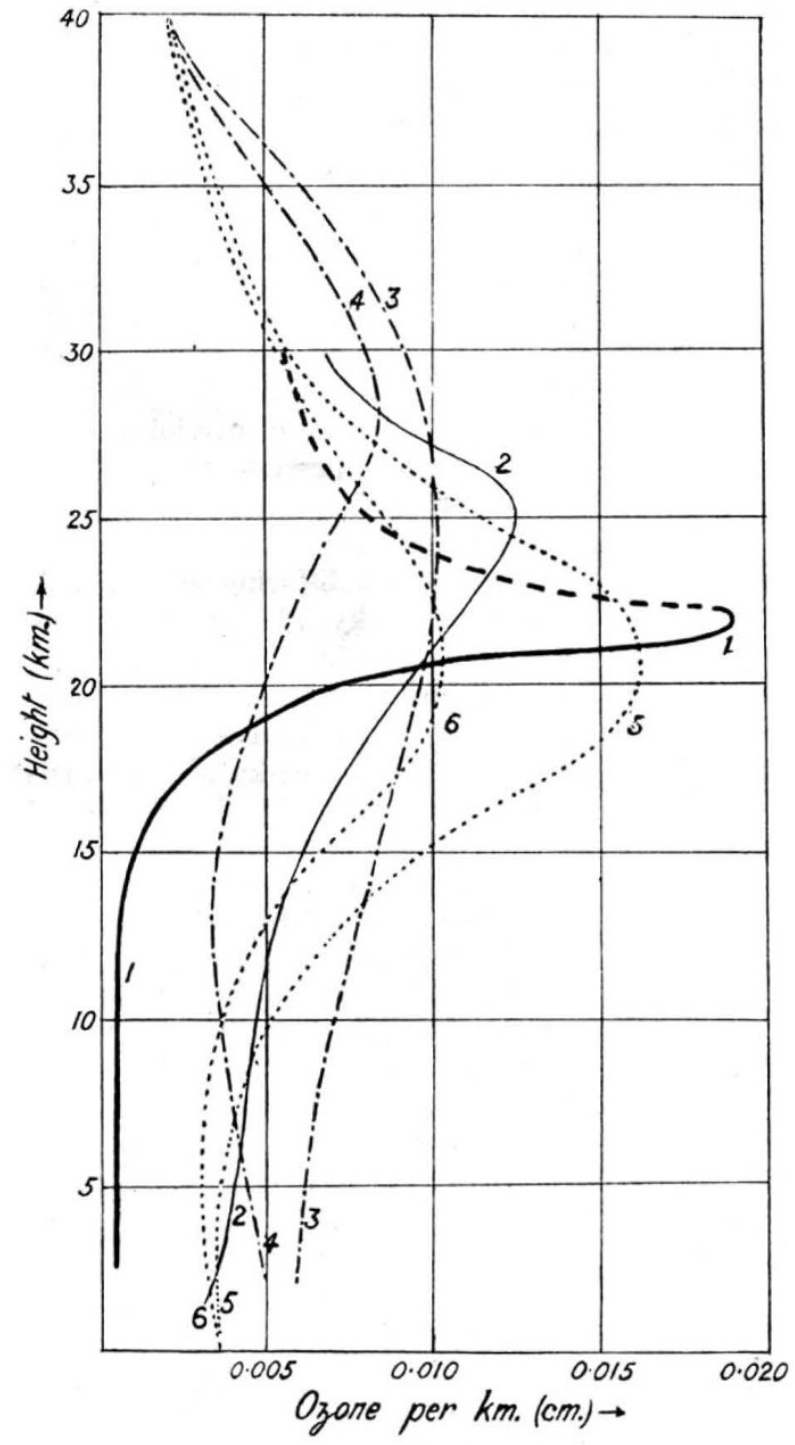

Fig. 2.

OZONE PER KILOMETRE AS A FUNOTION OF ALTITUDE.

CURve 1. Fught of Explorer II. Total ozone. $x=0.19$ CM. DOTTED PART DERIVED FROM SKY OBSERVATIONS.

CURVE 2. REGHNER'S SOUNDING BALLOON. $x=0.28 \mathrm{CM}$. CuRves 3 and 4. Ground determinations by Götz, Mempriam and Dobson at Arosa. Curve 3: $x=0.20$ cM. CURve $4: x=0.30$ cM.

Curves 5 and 6: Ground Determinations $\mathrm{BY}$ Meftham at Tromse. Curve $5: x=0.30 \mathrm{~cm}$. CuRve 6: $x=0.22$ cm.

Regener and others have measured the ionizing power of cosmic rays at different heights at the same latitude as Dakota; making certain assump- tions and neglecting the effect of nuclei of condensation, the positive conductivity should be

$$
\lambda_{+}=9.8 \times 10^{-6} \frac{T^{5 / 3}}{p} I^{\frac{1}{2}} .
$$

It is of great interest to compare this value with a direct determination.

Gish and Sherman constructed a rather ingenious modification of Gerdien's apparatus for measuring the conductivity. It consisted of a charged insulated rod in a cylindrical condenser through which air was aspirated. When the rod had lost a certain charge and therefore reached a critical potential, it was automatically recharged and a mark was made on a spiral record. By means of switches the potential to which the rod was charged could be made positive or negative and could be given various values, so that the same apparatus could be used for measuring positive and negative conductivities at several sensitivities.

The air conductivity was enormously greater at high altitudes than near the ground, but at all altitudes the positive and negative conductivities were in the constant ratio $0 \cdot 78$. This is not in agreement with laboratory experiments, but these are probably vitiated by free electrons. The conductivity on the descent was less than that on the ascent, but the authors believe that on the ascent the air was contaminated by gases from the balloon.

The conductivity was not equal to $9.8 \times$ $10^{-6} \frac{T^{5 / 3}}{p} I^{\frac{1}{2}}$, but it can be seen from Fig. 3 that from $3 \mathrm{~km}$. to $18 \mathrm{~km}$. it agreed very well with the formula

$$
\lambda_{+}=9.8 \times 10^{-6} \frac{T^{5 / 3}}{p} I^{\frac{1}{2}} \cdot\left(\frac{p}{p_{0}}\right)^{0.36}
$$

where $p_{0}$ is the pressure on the ground.

Below $3 \mathrm{~km}$. divergence from this value was to be expected because of the presence of nuclei of condensation. The authors suggest that the discrepancy above $18 \mathrm{~km}$. was either due to the fact that the air was not drawn sufficiently fast through the Gerdien condenser, or to the presence of more nuclei. Some support to the latter hypothesis is provided by the fact that a new air mass was encountered at about this height. That there can be nuclei of condensation in the stratosphere is proved by the occasional occurrence of mother of pearl clouds at $18-30 \mathrm{~km}$.

It is very much to be hoped that this work will be followed by further experiments with unmanned balloons. In any event Gish and Sherman are to be congratulated on a very valuable piece of work. They deduce a potential for the Heaviside layer of about 400,000 volts. 


\section{Air Composition}

In the troposphere, the air is being constantly mixed, and has almost perfectly uniform composition except with regard to water vapour and carbon dioxide. The great stability of air in the stratosphere to be expected from the absence of temperature gradient led people to expect that in this region each gas would behave independently

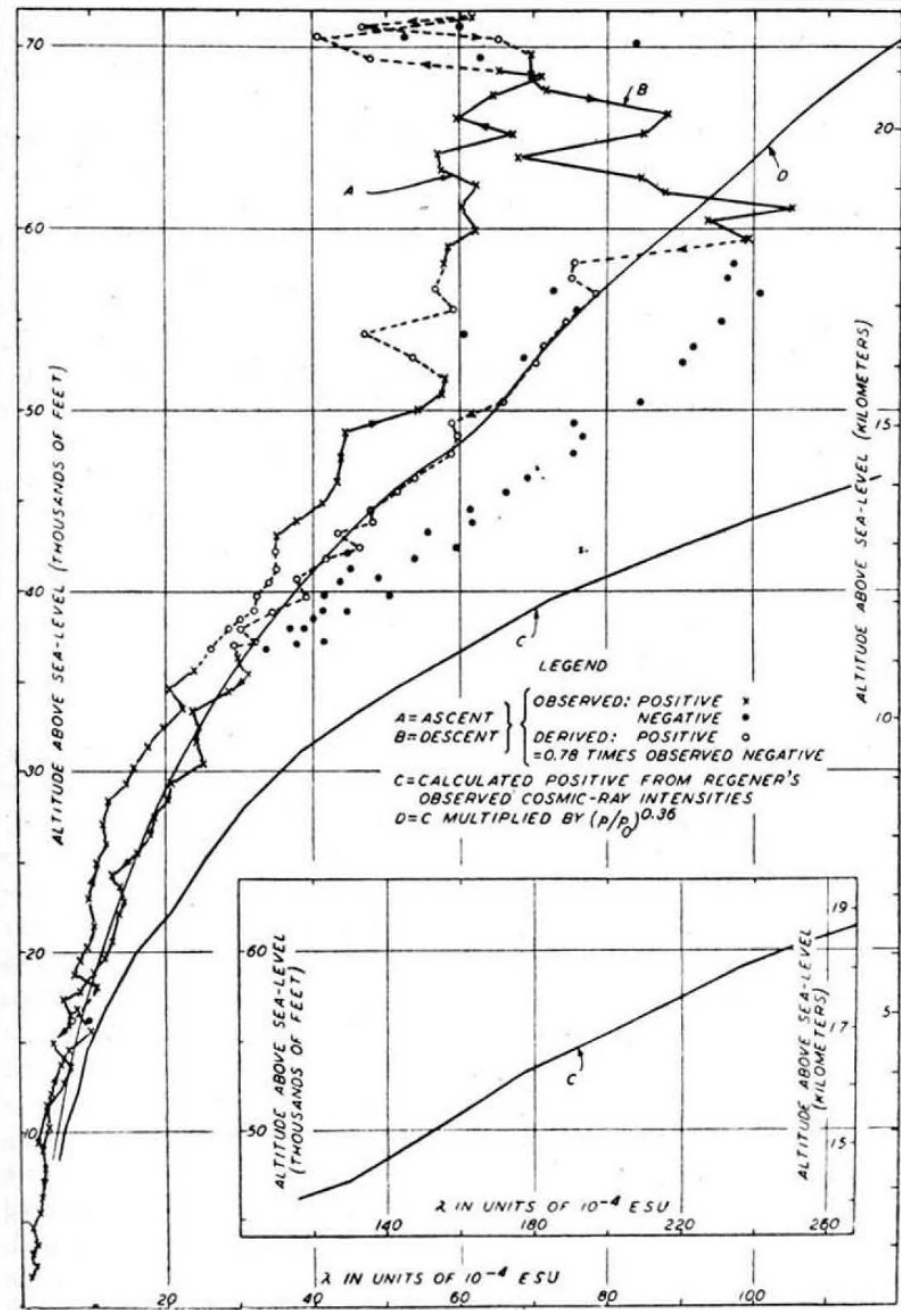

Fig. 3.

AIr CONDUCtivity, FLIGHT OF Explorer II NEAR RAPID City, SOUTH DAKOTA, November 11, 1935.

of the others, so that there should be an increasing preponderance of light gases at great heights, for example, hydrogen and helium. However, the behaviour of balloons in the stratosphere has shown the existence of considerable winds giving rise to mixing ; the extent to which this mixing is complete is of considerable interest to the geophysicist.

Various methods have been devised by which samples can be taken with unmanned balloons, and in England a good deal of work of this nature has been done by Paneth and Dines; with small sounding balloons, however, it is difficult to get large enough samples for very accurate analyses. Explorer II carried up three flasks, all of which were exposed at about $21.5 \mathrm{~km}$., just at the beginning of the descent. The third of these had a very ingenious valve for admitting air, but unfortunately this failed owing to the presence of a drop of oil in a capillary tube.

Paneth has shown that helium provides the best criterion of mixing, since the amount of hydrogen is everywhere negligible, and helium is the next lightest gas. The two samples were analysed for helium, oxygen and carbon dioxide, the former by measuring the residue when the other gases were absorbed in charcoal. The amount of helium was about fifty times what was to be expected, but this only shows that the air was contaminated by helium from the balloon.

Oxygen was determined both by absorption in potassium pyrogallate and by combustion with hydrogen. The two methods agreed well, and the final results were :

$$
\begin{array}{lr}
\text { Carbon dioxide } & 0.029 \pm 0.002 \\
\text { Oxygen } & 20.895 \pm 0.003
\end{array}
$$

At ground-level the proportion of oxygen is 20.945 per cent. The authors are uncertain whether the difference can be regarded as representative or whether under the peculiar weather conditions of the flight the air which they sampled was not brought down from even greater heights.

\section{MICRO-ORGANISMS}

Rogers and Meier performed experiments to determine whether there are any spores present in the stratosphere. It is well known that these can withstand great extremes of cold; their presence in the stratosphere would throw much light on the spread of micro-organisms, and would also demonstrate the mixing between stratosphere and troposphere air.

A special spore-collecting apparatus was devised which was dropped from the stratostat at 71,000 feet. It was carried down by a parachute which would open some time after leaving the balloon. As soon as the parachute opened the collector was exposed. It was afterwards closed by syphon bellows at $36,000 \mathrm{ft}$., which is just about the height of the base of the stratosphere. 
Every precaution was taken to avoid contamination, and on incubation on agar jelly at $30^{\circ} \mathrm{C}$. five colonies of bacteria and five moulds developed. The bacteria were all different and afterwards withstood temperatures much lower than those encountered on the stratosphere flight. The moulds were identified as Rhizopus, Aspergillus niger, Aspergillus fumigatus, Penicillium cyclopium and Macrosporium tenuis, all of which have frequently been collected on aeroplane flights.

\section{Conclusion}

A considerable amount of very useful data was obtained on this flight, and one has great admiration for the intrepid aeronauts who navigated the balloon, and the ground staff who made the flight possible. Nevertheless, one is inclined to wonder whether, from a purely scientific point of view, the money would not have been better spent in sending up a large number of unmanned balloons. Practically all the apparatus was entirely auto. matic in operation and it was merely necessary for the crew to press a few switches. It might be rather difficult to operate the cosmic ray apparatus and ozone spectrographs in an unmanned balloon, but Regener has succeeded in doing this. The total weight to be carried up was enormously increased, both by the passengers themselves and by the airtight stratostat with its air-conditioning apparatus. On the other hand, the popular appeal was far greater, which doubtless made it much easier to collect the necessary funds.

It is hoped that this flight will soon be repeated, as isolated observations become far more useful when substantiated by further data.

The report of the flight contains several very interesting photographs taken at the top of the flight. The most striking features in these pictures are the effects of erosion on the topography of South Dakota, and the sharpness of the top of the haze layer. Even more interesting are the photographs taken from an aeroplane at the exact moment of landing of the balloon.

R. T. P. W.

\section{Obituary Notices}

\section{Sir James Crichton-Browne, F.R.S.}

GIR JAMES CRICHTON-BROWNE, who died on $\checkmark$ January 31 at the age of ninety-seven years, was born at Dumfries in 1840. His father was Dr. W.A.F. Browne, who became Commissioner on Lunacy for Scotland, and was at the time of his son's birth head of a famous private asylum in Dumfries the Crichton Royal Institution. Crichton-Browne as a boy saw his father applying new methods to the treatment of the insane; they were treated as if they were rational human beings they were employed according to their bent in the day time, entertained in the evening and surrounded with the comforts of a home. His father believed in education-particularly of the young medical men who were to devote their lives to the care and treatment of insanity. It was in the late fifties of last century, when Crichton-Browne was a medical student in the University of Edinburgh, that Prof. Laycock of that University began to give lectures on the disordered psychology of the insane. In no other university or medical school in Great Britain was any attempt made to give systematic lectures on insanity It was otherwise on the Continent.

It cannot, therefore, be a matter of surprise to find young Crichton-Browne, when he became a qualified medical man in 1861 -he being then twenty-one years of age resolving to do for the insane of England what his father had done for their unfortunate brethren in Scotland. In the year in which he qualified, he gave a paper to the Royal Medical Society of London on "The Clinical Teaching of Psychology". It is difficult to believe, as one reads that lecture now, that its mature thoughts are those of a young man of twenty-one. "There are," said he, "in the midst of your civilization, currents swift and relentless which are ever hurrying on countless contributions to that whirlpool in the vortex of which so many minds float wrecked". The full and rounded style with which he enlightened his listeners in those later days was already developed in 1861 .

Newcastle-on-Tyne had discernment, and snapped up this young medical scot and placed him in charge of its asylum, and the medical school of that city made him its lecturer on medical psychology. While still in his twenties (1866), he was made medical director of the West Riding Asylum at Wakefield. $\mathrm{H}_{e}$ brought enlightened and humane methods with him, and believing that the foundation of all progress in medicine depends on research, had a laboratory built and equipped in connexion with the asylum. A glance at the reports which were issued under his direction will show how well he planned. The most famous of all the researches done there was that which laid the fame of the late Sir David Ferrier (1843-1928). In the spring of 1873, Ferrier visited the West Riding Asylum, Ferrier being then thirty years of age. Crichton-Browne was his senior by three years, they had been at the University of Edinburgh together. A discussion sprang up on the experiments which Fritsch and Hitzig had done on the brains of dogs. The result was that Ferrier stayed on to repeat similar experiments and ultimately proceeded to apply faradic stimulation to the cortex 